\title{
GIS technologies for selecting location of dams in the flood control systems
}

\author{
Mikhail Fedorov ${ }^{1}$, Vladimir Badenko ${ }^{1}$, Alexander Chusov ${ }^{1, *}$, and Vladimir Maslikov ${ }^{1}$ \\ ${ }^{1}$ Peter the Great St.Petersburg Polytechnic University, 195251, Polytechnicheskaya st. 29, St. \\ Petersburg, Russia
}

\begin{abstract}
Many floodplains are excluded from development because the floods cause considerable damage to people's lives and properties. Systems of hydraulic engineering structures for flood protection working with hydropower facilities are analysed to solve the problem of reducing the flood control volume of hydropower station. Methods of reducing the risk of flooding in the river basin by means of a distributed system of detention selfregulated dams are discussed. A geoinformation method used to justify the selection of parameters of such dams, primarily location of dam that minimize impact on the environment (ecological factor), is presented. In the present study, a system of multipurpose flood protection self-regulated dams is analysed as the measures for mitigation of flash floods in the Far Eastern region of Russia.
\end{abstract}

\section{Introduction}

Flood protection is one of the main development problems of modern society, related to environment. Flooding is a natural hazard which contributed to about $40 \%$ of worldwide natural disasters, so in many publications different measures for mitigation of flooding events have been discussed. In conditions of evidencing trend to global climate change, the goal becomes even more important, especially with concern of increasing of stream flow rate [1]. The issues of heavy rain floods are permanently exist in Russia, and in consequence of climate change, it is expected to further flood aggravation. During flood events in 2013, in consequence of heavy rains continued approximately about two months, large territories of the Far East and Northern-East China had inundated with catastrophic consequences [2]. In the middle of the 21 Century precipitation extremeness in summer period in in the Russian Far East is able to increase, therefore frequency and value of rainfall flood will grow up [1, 3].

According to modern approaches, flood protection of a territory is carried out according risk-based flood management as a system approach that assesses and compares the structural and non-structural measures to reach the optimal effects [4]. Traditional flood protection measures are orientated on existing situation and do not consider its uncertainty in the nearest future and further such as urbanization development, climate change and land utilization, and as a result, cost-expensive actions occurs inefficient [5]. These traditional measures focus on

\footnotetext{
*Corresponding author: chusov17@mail.ru
} 
the downstream catchment regions, and in flood control by structural measures has two different options: 1) within the specific basin flood storage capacities can be created in reservoirs which reduce the downstream flood flows and 2) flood-proofing measures (levees) are built which reduce the damage of floods but do not affect their runoff [6]. However, despite these options high flood risk results in excluding many floodplains in the downstream zone of hydropower station from sustainable development.

The decentralized flood protection measures have less influence on the environment, compared to the traditional ones. An appropriate concept is based on the idea of localization and usage of the capability of headwater areas of a flooded catchment to retard runoff as early as possible and at several places at the same time by means of flood detention dams with minimum environmental impact [7]. A distributed system of detentions dams with detentions reservoirs are a perspective flood mitigation approach to restore and improve the catchment's natural ability to retain storm runoff and to release it slowly, leading to attenuation of downstream flood peaks, whilst retaining or enhancing its ecosystem services [8,9]. Also it should be borne in mind that the hydrology of flood mitigation schemes with artificial reservoir storage is well understood and the discharge characteristics are largely controllable worldwide [10].

In addition, nature-based approaches for flood mitigation have gained popularity across Europe [11] known variously as natural flood (risk) management (NFM/NFRM), Natural Water Retention Measures (see http://www.nwrm.eu), or Working with Natural Processes (WwNP). Sometimes nature-based approaches are effective, including such techniques as afforestation of hillslopes to increase permeability and downslope transmissivity and so reduce saturated surface runoff and shelterbelts to intercept such flows, and tree cover also reduces effective precipitation [12]. In these connections, it should be noted some studies across Europe about natural water retention measure schemes, for example, in areas affected by the Central European floods of 2010 [13]. In some research a traditional hard engineered approach to flood mitigation was rejected due to cost and the relatively few properties benefiting, on the contrary a nature-based approach was proposed that made use of distributed, unsupervised, features [14].

In review [15], potentials of land-use planning and private flood precautionary measures as components of adaptation strategies for global change were analysed. Further damage increases due to floods are expected worldwide due to climate change and growing vulnerability. Therefore, to address the projected increase in flood risk, a combination of structural and non-structural flood risk mitigation measures must be considered as the most suitable adaptation strategy [16].

In many publications, the climate change is identified as a problem that prevents the selection of an effective strategy for the prevention of flood risk mitigation [1, 15, 17-24]. To account for the high uncertainty in climate change scenarios, it is advisable to include the maximum possible amount of climate model simulations [17]. To solve this problem the factors were calculated by comparing the model ensemble from phase 5 of the Coupled Model Intercomparison Project (CMIP5) with baseline historical climatology during two future periods (2020-49, period 1; 2070-99, period 2) [18]. It is noted that when assessing the impact of climate change on trends in heavy precipitation to hydrologic response according CMIP-5 atmosphere-ocean global circulation model (AOGCM), precipitation data should, be segregated based on concurrent soil moisture [19]. Because the potential impacts of climate change are an increasing focus of research, and ever-larger climate projection ensembles are available, making standard impact assessments more onerous, therefore some alternative ways were developed, for example, response surfaces, which present the change in a given indicator for a large number of plausible climatic changes defined on a regular sensitivity domain [20]. In [21], it was shown that over the last three decades the number of record-breaking events has significantly increased in the global mean. Globally, this increase 
has led to $12 \%$ more record-breaking rainfall events over 1981-2010 compared to those expected in stationary time series. The number of record-breaking rainfall events peaked in 2010 with an estimated $26 \%$ chance that a new rainfall record is due to long-term climate change. Also it was found that effects of anthropogenic changes in atmospheric composition are expected to cause climate changes, in particular an intensification of the global water cycle with a consequent increase in flood risk [22, 23]. Therefore, climate changes are becoming main subjects in flood protections researches [24].

Flood risk management has been discussed in scientific papers giving different meanings to the term and it can be find three different levels of actions for appropriate analyses: the operational level, which is associated with operating an existing flood protection system, a project planning level, which is used when a new, or a revision of an existing project is planned, and a project design level, which is embedded into the second level and describes the process of reaching an effective solution for the project [25]. In the present paper, questions belonged to the third level are discussed: the construction of stormwater detention basins, which is a one of the perspective management practice to effectively control of floods. Analyses of publications on appropriate flood protection measures has shown that detention reservoirs/basins in upstream areas may be considered as an effective flood protection measures to provide additional surface and volume storage for excess floodwater and to compensate for the adverse effects in downstream areas [26]. For flood diversion the usage dams, which do not need any operation management and could regulate water level automatically have been proposed [7]. Such types of structural measures named SelfRegulated Flood Dams (SRFD) for mitigation of flash floods are analysed in this paper as well considering climate changes. These dams are distributed in the river network and can store additional water volume caused by floods in temporary detention reservoirs/basins created by the SRFD system. A geoinformation method to justify the selection of parameters of the SRFD and appropriate basins, primarily the best location for the SRFD in a specific branch of the river network that minimize impact on the environment (ecological factor) [27] are presented.

\section{Methodology}

The development of methods to analyse how the site selection of SRFD meets the environmental criterion is the main objective of this paper. Appropriate modelling in the GIS environment of hydrological processes in a river basin, based on the basin-landscape approach to selection of modelling objects [28], is the methodological basis of the research.

Because ecological criterion is in the focus of the research, the following tasks are analyzed: rationale of appropriate SRFD parameters in specific location for SRFD, and calculation of flooding duration for each ecosystem/landscape for the particular SRFD parameters during flash floods. Based on the comparison of flooding duration for different location of the SRFD on the river with different SRFD's height and outlet system size the best SRFD parameters can be chosen.

The key question during modelling in GIS environment is appropriative selection of entities for modelling. This selection is based on the statement that in natural environment the main transfer of substance and energy is carried out by water. Therefore, the usage of drainage basins as entities for modelling is appropriate. But basins are not homogeneous. Hence a landscape structure of basins must be considering. Such reasoning leads to the need for usage of an integrated basin-landscape approach for selection of entities for modelling. The basin-landscape approach has a long successful story $[7,16,28,29]$ and the approach has proven their robustness.

Obviously, considered here SRFD have an impact on the environment and the main features of this impact are short duration, high-speed processes, and instability [7]. Among 
the environmental factors that are most frequently occur in the management of SRFD with temporarily flooded reservoirs/basins are following: the flooding of forest and wetlands, changing of river hydrology parameters, water quality, and fish migration violation [29], which will be analyzed. To justify the choosing of parameters and operation modes of SRFD, the ecological safety index is used, which is defined by the permissible area of short-term flooding of lands in the SRFD upstream. The area of flooding land and duration of flooding in our opinion determine the magnitude and type of changes in the natural environment of the landscapes of the river basin.

During modelling in GIS environment, a raster model is used for analyzed basins. The basic raster layers in the GIS database are landscapes (land use types) and the Digital Elevation Model (DEM). The method scheme is based on the experience in development of the method for estimation of gross hydropower potential in Russia [30]. For the selected scheme of flood management on a watershed, algorithms were developed and mathematical models of operational mode of the SRFDs controlling were implemented in the software, allowing variation of discharge structure parameters in order to determine the regulated flow at the tailrace, watermarks at the headrace, a water volume accumulation and a flood control discharge, areas and duration of land flooding [7]. Steps for method proposed are described further.

1. The first step is to create GIS database layers with sub-basins for the drainage basins in interest. For this purpose according modern approaches based on DEM is used. Although DEMs may be useful for several hydrological applications, they are often containing uncertainty. These uncertainties have the potential to greatly influence on DEM-derived attributes including derived untrue surface drainage patterns [31]. However, experience of practical applications shows, that DEM can accurately replicate both landscape form and processes [32]. DEMs are very useful to support modelling of flood events [33]. Topographic accuracy, methods of preparation and grid size are all important for hydrodynamic models to efficiently modelling of flow processes [34]. In areas with a monsoon climate in the Far East of Russia there are many areas, which are prone to heavy flooding. Also these areas are remote, which are data-scarce regions and high resolution DEMs derived from topography survey are usually not available. Therefore, it is necessary to use lower resolution data such as the Shuttle Radar Topography Mission (SRTM) and Advanced Spaceborne Thermal Emission and Reflection Radiometer (ASTER) for use within hydrodynamic models [35].

2. Second step is creation of a virtual river network, which is corresponded to DEM. The usage of synthetic rivers is an appropriate solution. Synthetic rivers are mathematical models of river networks, calculated from the DEM using thalweg tracing. Comparison of synthetic rivers and rivers obtained from digital maps has showed that the tributary's sites match well, but the source of real rivers and synthetic rivers sometimes don't match [34]. This is due to the fact, that finding the springhead of a real river always needs a complex study. At the same time the springhead location of a synthetic river (as well as synthetic rivers network density) depends on a set of conditions in the algorithm [7]. In this research a calculation of flow direction on the base of DEM is performed, as a result thalwegs is defined [36].

3. On the next step, landcover (landscape) layer in GIS environment must be created. This layer usually is a raster layer. Classes for this layer can be different for different areas and tasks. For each class is assigned a possible flooding time, during which there are no irreversible changes in the landscape.

4. To justify the parameters of the SRFD, special software using programming language Phyton has been developed. The results of calculations were obtained in the form of graphs and thematic GIS maps. For the software the basic raster layers in the GIS database are following: landscapes (landcover types) $\{L S\}$ and DEM $\{D T\}$. For these layers, the pixels of the equal size are used. The main resulting layer is a raster layer $\{T f\}$ with the flooding time as an attribute which depends on the specific parameters of SRFD and flood hydrograph. 
Let $\mathrm{X}$ is the location of the SRFD on the river; $\mathrm{w}$ is the width of the SRFD hole (outlet system size), $\mathrm{Hd}$ - the height of the SRFD. In each location X maximum volume of detention flood water $\mathrm{Vm}=\mathrm{F}(\mathrm{Hd})$ can be calculated on the base of DEM. Let in the basin there are $\mathrm{N}$ landscapes. One of the criteria for selection of the $\mathrm{X}$ is the relation of the detention basin storage capacity $(\mathrm{Vm})$ to the runoff which is generated in the drainage basin corresponded to the $\mathrm{X}(\mathrm{Pr}(\mathrm{X}))$.

Let for every $\mathrm{j}$-th landscape, a critical TSj flooding time, beyond which for the $\mathrm{j}$-th landscape will be an environmental hazard, is known. Let $\mathrm{HYD}(\mathrm{t})$ is the a is a hydrograph of a specific flood in the $\mathrm{X}(\mathrm{t}-\mathrm{time}) . \mathrm{H}(\mathrm{t})$ is the water level in the SRFD upstream (before flood $H(t)=$ Const $)$. Flooding begins at time $t=0$. At each time step software calculates $H(t)$ :

$$
\mathrm{H}(\mathrm{t})=\mathrm{f}(\mathrm{X}, \mathrm{w}, \mathrm{Hd},\{\mathrm{DT}\}, \mathrm{HYD}(\mathrm{t}-1), \mathrm{H}(\mathrm{t}-1))
$$

$\mathrm{H}(\mathrm{t})<\mathrm{Hd}$. On the basis of $\mathrm{H}(\mathrm{t})$ can define a set of pixels which are flooded at time $\mathrm{t}$ : $\{L S\}_{t}$. Then for each landscape software calculates the flooding time:

$$
\left\{\mathrm{Tf}_{\mathrm{j}}=\sum_{\mathrm{t}}\{\mathrm{LS}\}_{\mathrm{t}}\right.
$$

Then the condition to select the best location $\mathrm{X}$ for the SRFD can be written as:

$$
\sum_{\mathrm{j}}\{\mathrm{Tf}\}_{\mathrm{j}} \rightarrow \min \left\{\mathrm{Tf}_{\mathrm{j}}<\mathrm{TS}_{\mathrm{j}}\right.
$$

Also $\mathrm{V}(\mathrm{t})=\mathrm{F}(\mathrm{H}(\mathrm{t}))$ can be calculated by software developed. $\mathrm{V}(\mathrm{t})$ can considered as the SRFD effectiveness as a measure for mitigation of flood events. In addition, a regional planning should be considered. In Russian Federation for each region there are plans for regional development. The program checks whether the set $\{L S\}_{t}$ is in contradiction with the regional planning. Climate change is considered by calculating the difference in precipitation in the wettest month between the current state and forecasts for 2050 and 2070.

\section{Results and discussion}

Selemdzha river basin in Far East monsoon region of the Russian Federation is considered as example for testing of the method proposed. Satellite images of river basin at the SRFD locations are used for determining the flood hazard area corresponding to water plane of flood passing with different probability. The vector and raster layers in GIS database have been created to simulate the hydrological processes in the basin territory (fig.1).

a)

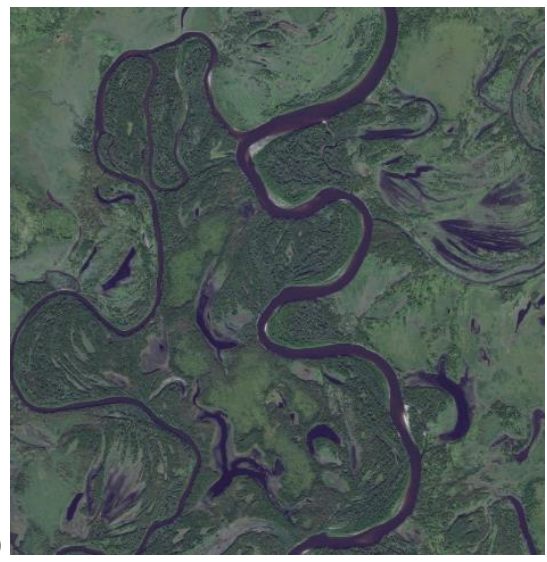

b)

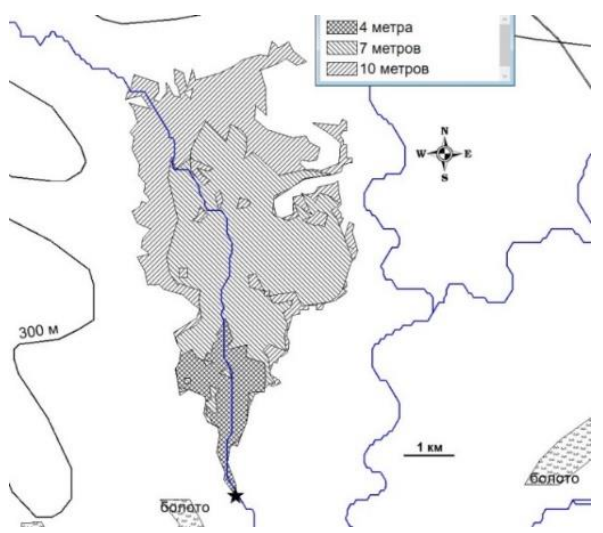

Fig. 1. Typical part of the Selemdgha river basin: a) a satellite image; b) flooding zones. 
Simulation is complicated by the fact that changes in the watercourse are typical for rivers in the investigated area, as is clearly seen in fig. 1a (a satellite image), and this creates additional difficulties. In fig $1 \mathrm{~b}$ different flooding areas are shown. The result of first step of the method - creation of DEM for Selemdgha river in fig. 2 is shown. Also in fig. 2 is shown the synthetic rivers network, which is created using thalweg of DEM (result of step 2).

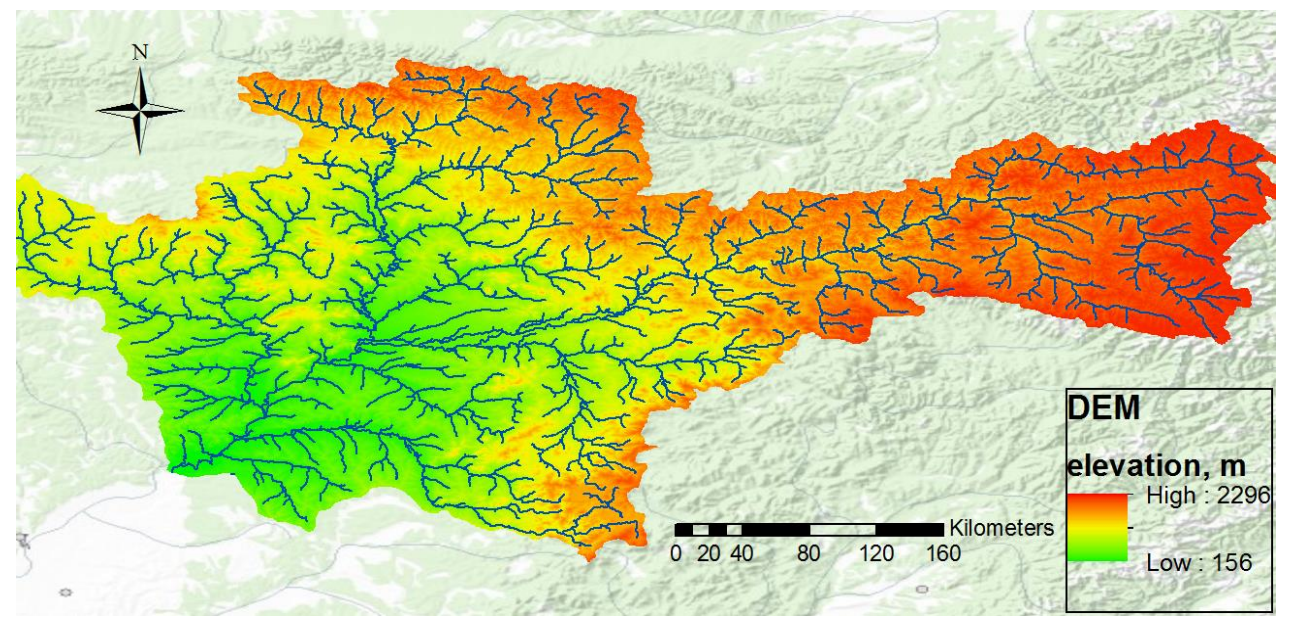

Fig. 2. DEM for Selemdgha river (Far East of Russia).

Fig. 3 shows the results of testing the developed software and the proposed method: a thematic GIS map for flooding for the specific site selection of SRFD ( $\{L S\}_{t}$ for using in (2) formula). Flooding time duration for specific $w$ is shown with different colour. Pixel size for the raster GIS database is 100 meters. Using GIS-technologies, the flooding areas were defined depending on the flood water level of different probability. Analysis of results in form of thematic maps, like in fig. 3 can shows how the SRFD site selection meets the environmental criterion. This approach has been used to justify selection of SRFD parameters; primarily the height of a dam and its location on a water course, providing minimization of the environmental impact is secured.
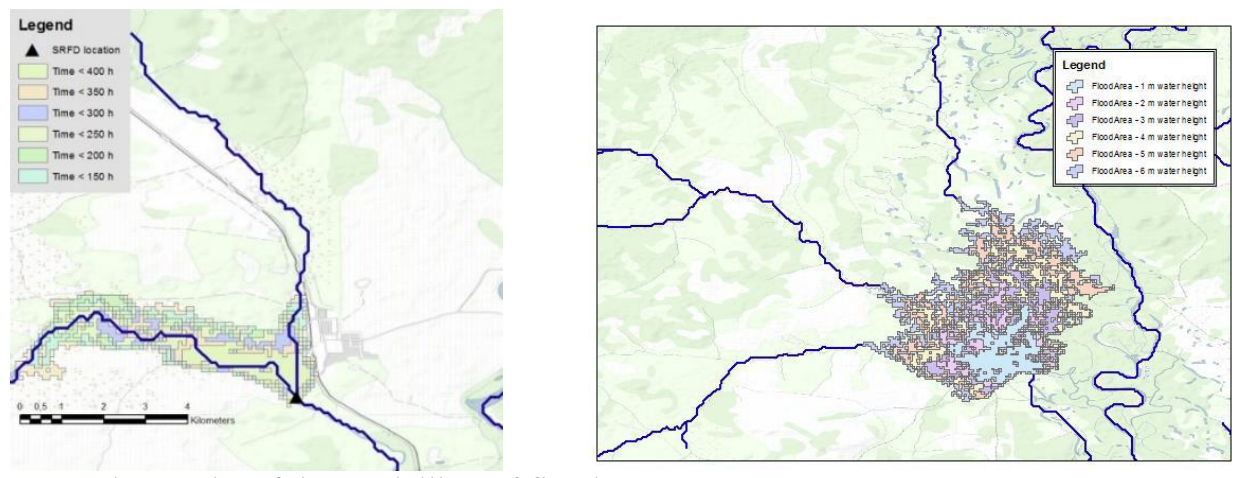

Fig. 3. The results of the modelling of flood zones.

As GIS software free version of QGIS is used. In fig.4 a screenshot of appropriate dialog for analysis of harmonisation of regional planning database and a SRDF flooding zones is shown. In fig. 4 green spots depict special protected environmental zones. These zones need a special analysis for artificial flooding by the SRFD. 


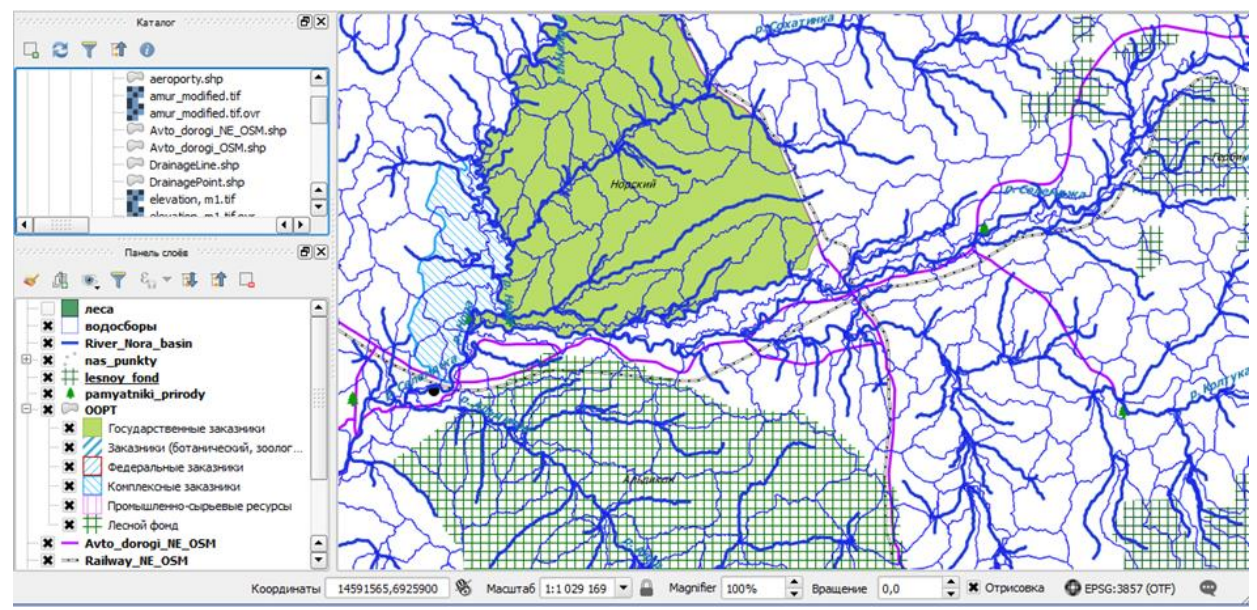

Fig. 4. A fragment of dialog in QGIS with regional planning database.

A fragment of climate changes analysis on study region is shown in fig.5.

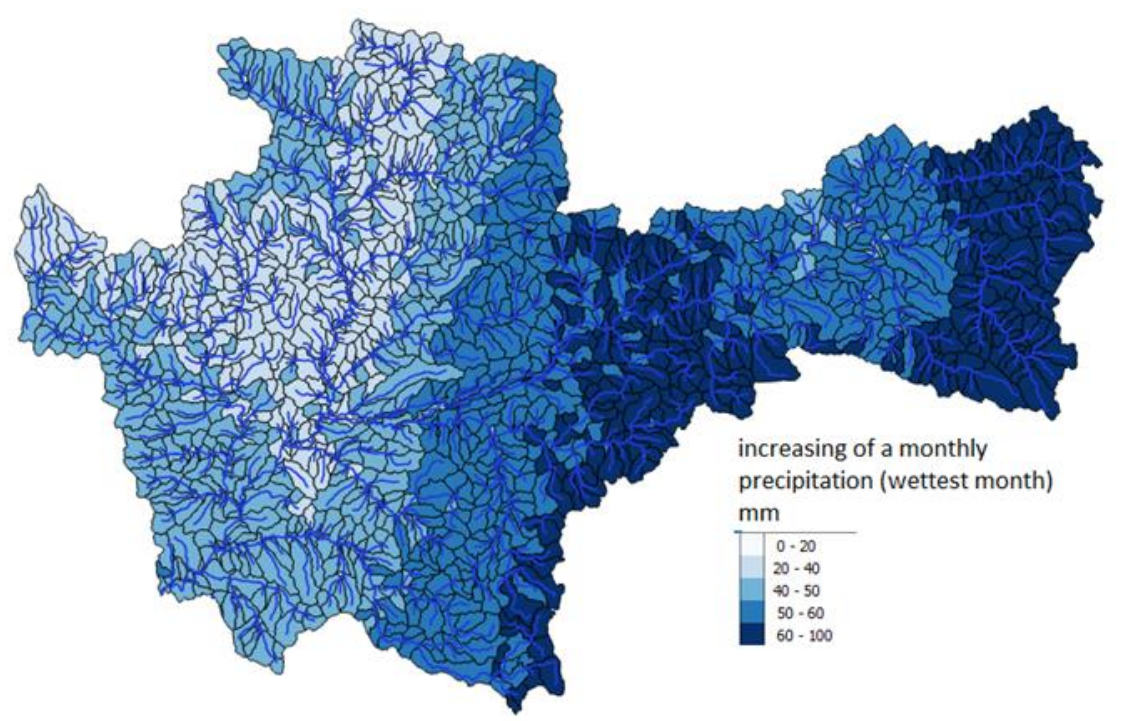

Fig. 5. A thematic GIS map with result of climate changes result.

For the analysis, the IPCC data was used (http://www.worldclim.org/CMIP5_30s) with a resolution of 30 seconds [37]. Four scenarios were downloaded in raster format for two time periods (2050 for the average for 2041-2060 and 2070 for the average for 2061-2080) for three models: BCC-CSM1-1, CCSM4, HadGEM2-ES. Scenarios are the trajectories of greenhouse gas concentrations adopted by the IPCC in the fifth report (Assessment Report (AR5)) in 2014. They are used for climate modelling and research. They describe the four possible climate futures, depending on how much greenhouse gases are emitted in the coming years. The four scenarios (RCP2.6, RCP4.5, RCP6, and RCP8.5) are named according possible range of radiation exposure values in 2100 compared to pre-industrial values $(+2.6$, $+4.5,+6.0$, and $+8.5 \mathrm{~W} / \mathrm{m}^{2}$ respectively). 


\section{Conclusions}

At the present time, methodologies for the river network modelling with the use of GIS are fairly well developed. Satellite images of river basin at the SRFD locations are usually used for determining the flood hazard area corresponding to water plane of flood passing with different probability, designed with use of digital elevation model in GIS environment. Some scenarios for branches were developed for the river Selemdzha - Nora basin. The vector and raster layers in GIS database have been created to simulate the hydrological processes in the basin territory. The results of calculations performed by means of computer software coded using the Python language was obtained in the form of graphs and thematic GIS maps.

Using GIS-technologies, the flooding areas were defined depending on the flood water level of different probability. Detention reservoirs are structural measures for protection against the flash flood events.

As a measure for mitigation of flash floods, the authors have analysed regulation of river flow by a system of detention reservoirs for flood diversion with dams located in the Russian Far East, which do not need any operational management. A method for analysis, how the dam site selection meets the environmental criterion has been developed. This method has been used to justify selection of a self-regulated flood dam parameters, primarily the height of a dam and its location on a water course, providing minimization of the environmental impact is secured.

Raster GIS database layer was combined with the landscape layer and critical time points to fit ecological criterion. This allowed a comparison of one site for SRFD with others and chooses the best location that has a minimal impact on the environment. If ecological management concerning risk-based flood management define as a system approach that assesses and compares the structural and non-structural measures to pursue the best ameliorating effects, then the method proposed can solve some sustainable urban development problem in flood-prone areas considering environmental impact [8]. The method proposed adapts the principles supporting structural measures as protection of coastal urban area by making room for water and save natural landscapes.

\section{Acknowledgement}

This work is supported by the Russian Science Foundation under grant № 16-17-00050.

\section{References}

1. N.W. Arnell, S.N. Gosling, Climatic Change 134, 387-401 (2016)

2. M.V. Bolgov, N.I. Alekseevskii, B.I. Gartsman, V.Yu. Georgievskii, I.O. Dugina, V.I. Kim, A.N. Makhinov, A.L. Shalygin, Geography and Natural Resources 36, 225-233 (2015)

3. A.B. Avakyan, M.N. Istomina, Power Technology and Engineering 35, 89-93 (2001)

4. C. Butler, N. Pidgeon, Environment and Planning C: Government and Policy 29, 533547 (2011)

5. Z.W. Kundzewicz, N. Lugeri, R. Dankers, Y. Hirabayashi, P. Döll, I. Pińskwar, T. Dysarz, S. Hochrainer, P. Matczak, Mitigation and Adaptation Strategies for Global Change 15, 641-656 (2010)

6. J. Leandro, A. Schumann, A. Pfister, Journal of Hydrology 535, 356-365 (2016)

7. M. Fedorov, V. Badenko, V. Maslikov, A. Chusov, Procedia Engineering 165, 1629$1636(2016)$ 
8. N.J. Barber, P.F. Quinn, Area 44(4), 454-462 (2012)

9. O. Ionuş, M. Licurici, M. Pătroescu, S. Boengiu, Natural Hazards 75(1), 69-88 (2014)

10. V.I. Danilov-Danilyan, A.N. Gelfan, Y.G. Motovilov, A.S. Kalugin, Water resources 41(2), 115-125 (2014)

11. E. Kiedrzyńska, M. Kiedrzyński, M. Zalewski, Natural Hazards 76(2), 955-977 (2015)

12. H. Wheater, E. Evans, Land Use Policy 26, 251-264 (2009)

13. D. Skublics, P. Rutschmann, Natural Hazards 75(1), 51-67 (2015)

14. A.R. Nicholson, M.E. Wilkinson, G.M. O'Donnell, P.F. Quinn, Area 44(4), 463-469 (2012)

15. H. Kreibich, P. Bubeck, M. Van Vliet, H. De Moel, Mitigation and Adaptation Strategies for Global Change 20(6), 967-989 (2015)

16. M. Fedorov, V. Badenko, V. Maslikov, A. Chusov, MATEC Web of Conferences 73, 01002 (2016)

17. V. Ntegeka, P. Baguis, E. Roulin, P. Willems, Journal of Hydrology 508, 307-321 (2014)

18. G.Zhao, H.Gao, L.Cuo, Journal of Hydrometeorology 17(9), 2371-2389 (2016)

19. T.J. Ivancic, S.B.Shaw, Climatic Change 133(4), 681-693 (2015)

20. A.L. Kay, S.M. Crooks, N.S. Reynard, Hydrological Processes 28(20), 5273-5287 (2014)

21. J. Lehmann, D. Coumou, K. Frieler, Climatic Change 132(4), 501-515 (2015)

22. P.C.D. Milly, R.T. Wetherald, K.A. Dunne, T.L. Delworth, Nature 415(6871), 514-517 (2002)

23. Z.W. Kundzewicz, Ecohydrology \& Hydrobiology 8(2), 195-203 (2008)

24. C. Prudhomme, R.L. Wilby, S. Crooks, A.L. Kay, N.S. Reynard, Journal of Hydrology 390(3), 198-209 (2010)

25. L. Wang, J. Yu, Hydrological Processes 26(19), 2973-2984 (2012)

26. E.J. Plate, Journal of Hydrology 267, 2-11 (2002)

27. M.P. Fedorov, A.G. Bogolyubov, V.I. Maslikov, Hydrotechnical Construction 29, 353 357 (1995)

28. N.V. Aref'ev, V.L. Badenko, G.K. Osipov, Power Technology and Engineering 32, 660663 (1998)

29. V. Badenko, N. Badenko, A. Nikonorov, D. Molodtsov, V. Terleev, J. Lednova, V. Maslikov, MATEC Web of Conferences 73, 03003 (2016)

30. T.S. Ivanov, N.V. Badenko, V.A. Oleshko, Magazine of Civil Engineering 4(39), 70-82 (2013)

31. K. Woodrow, J.B. Lindsay, A.A. Berg, Journal of Hydrology 540, 1022-1029 (2016)

32. D. Nijssen, A. Schumann, M. Pahlow, B. Klein, Natural Hazards and Earth System Science 9, 1349-1363 (2009)

33. P.A. Brivio, R. Colombo, M. Maggi, R. Tomasoni, International Journal of Remote Sensing 23(3), 429-441 (2002)

34. V. Merwade, A. Cook, J. Coonrod, Environmental Modelling \& Software 23(10-11), 1300-1311 (2008)

35. A.A. Jarihani, J.N. Callow, et.al. Journal of Hydrology 524, 489-506 (2015)

36. R.F. Vázquez, J. Feyen, Journal of Hydrology 387(1-2), 128-140 (2010)

37. L. Drouet, V. Bosetti, M. Tavoni, Nature climate change 5(10), 937-940 (2015) 